\title{
Stereoselective Synthesis of Vinylsilanes by a Gold(I)-Catalyzed Acetylenic Sila-Cope Rearrangement
}

Yoshikazu Horino, Michael R. Luzung, and F. Dean Toste*

Department of Chemistry, University of California, Berkeley, California 94720

Received May 25, 2006; E-mail: fdtoste@uclink.berkeley.edu

Recent advances have dramatically increased the utility of organosilanes and silanolates as reagents for metal-catalyzed crosscoupling reactions. ${ }^{1}$ The application of these reactions to stereoselective olefin synthesis is contingent on efficient and selective methods for the construction of vinylsilanes. Metal-mediated stereoselective addition to alkynes is commonly employed for this purpose. ${ }^{2}$ For example, trans-allylsilylation ${ }^{3}$ of alkynes and cisallylmetalation of silylacetylenes ${ }^{4}$ allow for the stereoselective construction of 1,4-dienylsilanes in which the allyl group is trans to silicon. On the other hand, application of allylmetalation reactions to the stereoselective synthesis of olefins substituted with the allyl group cis to silicon is rare. ${ }^{5}$ The gold(I)-catalyzed rearrangement of propargyl vinyl ethers, which is hypothesized to proceed through a cyclization-induced rearrangement, was recently reported. ${ }^{6} \mathrm{We}$ envisioned that gold(I)-induced 6-endo-dig cyclization of acetylenic allylsilanes ${ }^{7}$ would initiate a related rearrangement and provide a method for the stereoselective synthesis of cis-1,4-dienylsilanes. ${ }^{8}$

To this end, treatment of dimethylsilane 1a with catalytic amounts of cationic tri-tert-butylphosphinegold(I), in the presence of 3 equiv of methanol, furnished 1,4-diene $\mathbf{2 a}$ in $78 \%$ yield after $1 \mathrm{~h}$ at room temperature (eq 1). ${ }^{9}$ While this reaction provided a general route to 2,2-disubstituted-1,4-dienes, it failed to afford the desired vinylsilane. We surmised that $\mathbf{2}$ was being formed through the desired rearrangement followed by rapid protodesilation of the resulting vinylsilane.

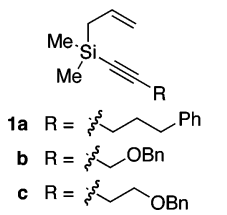

$$
\begin{array}{ll}
\stackrel{5 \%\left(t-\mathrm{Bu}_{3} \mathrm{P}\right) \mathrm{AuCl}, 5 \% \mathrm{AgSbF}_{6}}{\mathrm{CH}_{2} \mathrm{Cl}_{2}, \mathrm{MeOH} \text { (3 equiv), rt }} & \text { 2a } 78 \% \\
& \text { b } 71 \% \\
& \text { c } 74 \%
\end{array}
$$

In accord with this hypothesis, gold(I)-catalyzed rearrangement of more robust diphenylsilane $\mathbf{3}$ furnished a mixture of silacycle 4a and vinylsilane 5a which slowly converted into 1,4-diene $\mathbf{2 a}$ (Table 1, entries 1-3). ${ }^{10}$ Changing the silver additive from $\mathrm{AgSbF}_{6}$ to $\mathrm{AgBF}_{4}$ resulted in improved selectivity for the formation of silacycle 4a without deterioration of reaction efficiency (entry 4). While changing the sterics of the alcohol did not divert the reaction pathway from silacycle formation (entries 5-7), the use of phenol as a nucleophile completely reversed the selectivity in favor of vinylsilane 5e (entry 8).

With these conditions in hand, the substrate scope of the gold(I)-catalyzed rearrangements was probed (Table 2). We were pleased to find that substitution at the acetylenic position $\left(\mathrm{R}^{1}\right)$ of allylsilane 6 was well tolerated and that the selectivity for cyclic and acyclic products is generally retained. For example, the gold(I)-catalyzed reaction of propargyl alcohol $\mathbf{6 f}$ produced silacycle $7 \mathbf{k}$ in $76 \%$ yield in the presence of 3 equiv of methanol (entry 11). When the nucleophile was changed to phenol, the reaction course was completely diverted to generate vinylsilane $\mathbf{8 1}$ in $68 \%$ yield (entry 12). Notably, rearrangement of 1,5 -enyne $\mathbf{6 g}$ resulted in exclusive
Table 1. Catalyst Optimization

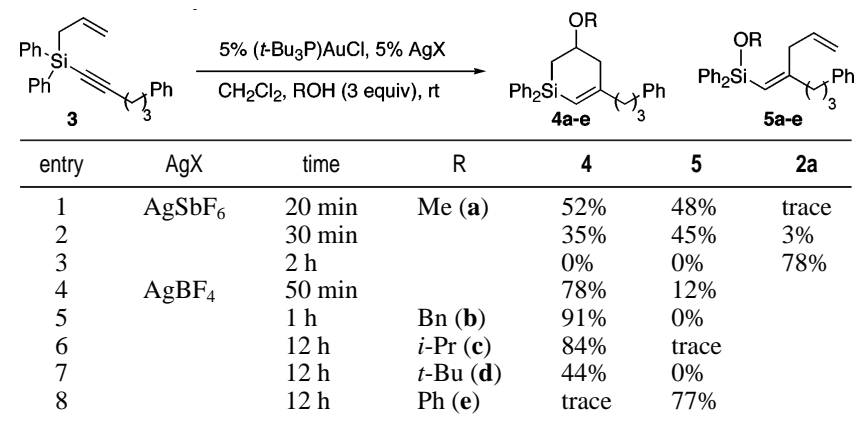

Table 2. Scope of Gold(I)-Catalyzed Sila-Cope Rearrangement ${ }^{a}$

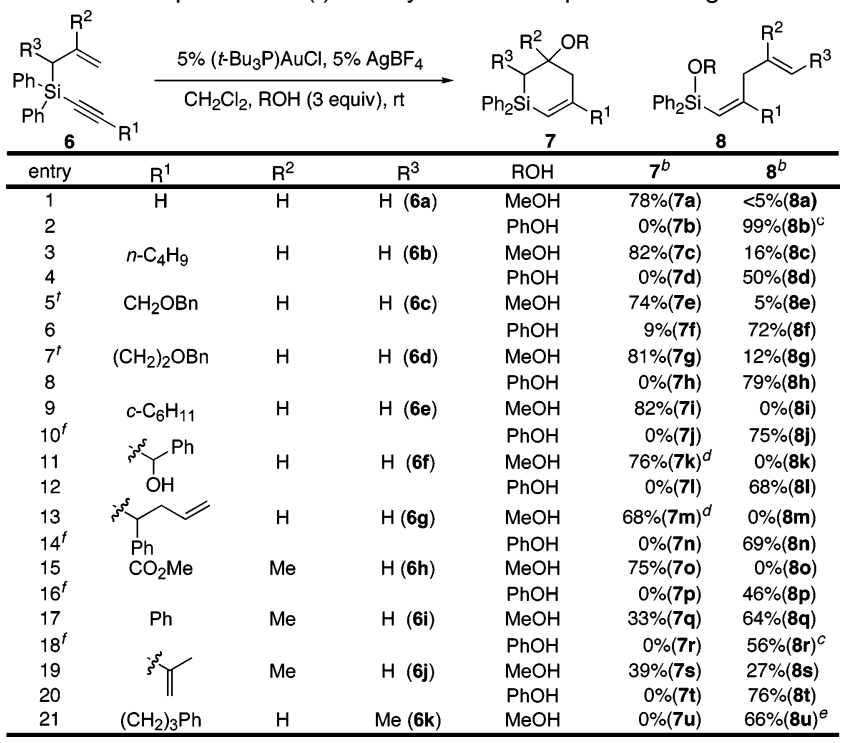

${ }^{a}$ Reaction conditions: $0.2 \mathrm{M} 6$ in $\mathrm{CH}_{2} \mathrm{Cl}_{2}$, rt. ${ }^{b}$ Isolated yield after chromatography. ${ }^{c} 7-8: 1$ mixture of olefin isomers. ${ }^{d} 1: 1$ mixture of diastereomers. ${ }^{e} 2: 1$ mixture of crotyl olefin isomers. ${ }^{f}$ Run at $50{ }^{\circ} \mathrm{C}$.

formation of desired adducts without significant competing enyne cycloisomerization (entries 13 and 14). ${ }^{11,15 c}$

Substitution on the allyl moiety is also tolerated but has consequences on the product distribution. For example, C2substituted allylsilane $\mathbf{6 h}$ underwent the gold(I)-catalyzed cyclization onto an alkynoate to afford silacycle 70 in $75 \%$ yield (entry 15) and vinylsilane $\mathbf{8 p}$ in $46 \%$ yield (entry 16) in the presence of methanol and phenol, respectively. It is noteworthy that, in contrast to typical $\beta$-addition of nucleophiles to alkynoates, ${ }^{8 \mathrm{c}}$ in this reaction, allylsilane regioselectively adds to the $\alpha$-position. On the other hand, substituted allylsilanes $\mathbf{6 i}$ and $\mathbf{6 j}$ underwent addition of methanol to provide mixtures of cyclic and acyclic products (entries 17 and 19); however, the gold(I)-catalyzed reaction of phenol with $\mathbf{6 i}$ and $\mathbf{6 j}$ afforded vinylsilanes $\mathbf{8} \mathbf{r}^{12}$ and $\mathbf{8 t}$, respectively (entries 18 and 20). Furthermore, gold(I)-catalyzed rearrangement of an allylsilane (6k) that is substituted adjacent to the silicon produced vinylsilane 
Scheme 1. Proposed Mechanism of $\mathrm{Au}(\mathrm{l})$-Catalyzed Rearrangement

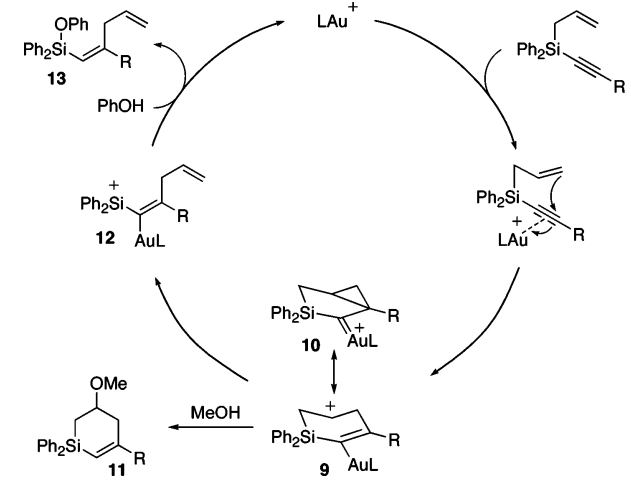

product $\mathbf{8 u}$ even when methanol was employed as a nucleophile (entry 21).

A proposed mechanism involving $\mathrm{S}_{\mathrm{E}} 2^{\prime}$ addition of the allylsilane onto a gold(I)-complexed alkyne to generate a gold-stabilized cation is outlined in Scheme $1 .{ }^{13}$ While $\beta$-silyl fragmentation is generally faster than trapping of the cation, ${ }^{14}$ stabilization of 9 by backbonding from gold(I) (i.e., resonance structure 10 ${ }^{15}$ allows for methanol addition to afford cyclic silane 11. On the other hand, when the relative rate of nucleophilic trapping is decreased, selective trapping occurs at silyl cation $\mathbf{1 2}$ to afford vinylsilane $\mathbf{1 3}$. Presumably, this is the case when the less nucleophilic phenol is used and when addition to the cation is sterically encumbered (Table 2 , entries 17 and 19). Furthermore, an increase in the relative rate of $\beta$-silyl fragmentation as a result of the steric clash of the methyl group and the silicon substituents accounts for the observation that $\alpha$-substituted allylsilane $\mathbf{6 k}$ affords only vinylsilane $\mathbf{8 u}$ (Table 2, entry 21).

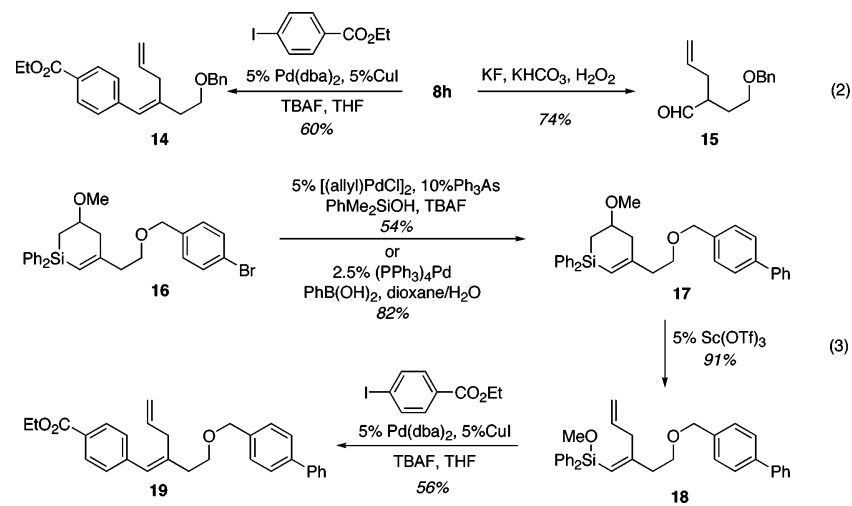

The products of the gold(I)-catalyzed acetylenic sila-Cope rearrangement serve as useful reagents in a number of transformations. For example, palladium-catalyzed cross-coupling ${ }^{1}$ of vinylsilane $\mathbf{8 h}$ with ethyl 4-iodobenzoate produced trisubstituted olefin 14 in $60 \%$ yield (eq 2). Moreover, $\alpha$-allylated aldehyde 15 was prepared through a Tamao oxidation ${ }^{16}$ of $\mathbf{8 h}$. Additionally, the silacycles can be viewed as latent vinylsilanes that can be revealed on treatment with a mild Lewis acid. This allowed for chemoselective cross-coupling reactions of arylbromide $\mathbf{1 6}$ to be performed, while the vinyl silane remained protected as the silacycle (eq 3). Reaction of 17 with $5 \mathrm{~mol} \%$ of $\mathrm{Sc}(\mathrm{OTf})_{3}$ generated vinylsilane 18, which was subjected to a second cross-coupling reaction to afford trisubstituted olefin $\mathbf{1 9 .}$

In conclusion, a cationic gold(I) complex has been developed as a catalyst for the first transition-metal-catalyzed acetylenic silaCope rearrangement. ${ }^{17}$ The reaction allows for the stereoselective synthesis of vinylsilanes substituted with a wide range of functional groups. Furthermore, depending on the choice of nucleophile, either cyclic or acyclic vinylsilanes were produced. Both of these reagents can be employed for stereoselective synthesis of trisubstituted ${ }^{18}$ olefins through transition-metal-catalyzed cross-coupling reactions.

Acknowledgment. We gratefully acknowledge the University of California, Berkeley, NIHGMS (R01 GM073932-01), Merck Research Laboratories, Bristol-Myers Squibb, Amgen Inc., DuPont, GlaxoSmithKline, Eli Lilly \& Co., Pfizer, AstraZeneca, Abbott, and Roche for financial support. Y.H. thanks JSPS for a postdoctoral fellowship.

Supporting Information Available: Experimental procedures and compound characterization data. This material is available free of charge via the Internet at http://pubs.acs.org.

\section{References}

(1) (a) Denmark, S. D.; Baird, J. D. Chem.-Eur. J. 2006 12, 4954. (b) Denmark, S. E. Sweis, F. In Metal-Catalyzed Cross-Coupling Reactions, 2nd ed.; De Meijere, A., Diderich, F., Eds.; Wiley-VCH: Weinheim, Germany, 2004; Chapter 4. (c) Hiyama, T.; Shirakawa, E. Top. Curr. Chem. 2002, 219, 61 .

(2) (a) Trost, B. M.; Ball, Z. T. Synthesis 2005, 6, 853. (b) Marek, I.; Chinkov, N.; Banon-Tenne, D. In Metal-Catalyzed Cross-Coupling Reactions, 2nd ed.; De Meijere, A., Diderich, F., Eds.; Wiley- VCH: Weinheim, Germany, 2004; Chapter 4. (c) Normant, J. F.; Alexakis, A. Synthesis 1981, 902

(3) For Lewis acid-mediated trans-allylsilylation, see: (a) Yeon, S. H.; Han, J. S.; Hong, E.; Do, Y.; Jung, I. N. J. Organomet. Chem. 1995, 499, 159. (b) Asao, N.; Yoshikawa, E.; Yamamoto, Y. J. Org. Chem. 1996, 61 4874. (c) Yoshikawa, E.; Gevorgyan, V.; Asao, N.; Yamamoto, Y. J. Am Chem. Soc. 1997, 119, 6781. For a review, see: (d) Asao, N.; Yamamoto, Y. Bull. Chem. Soc. Jpn 2000, 3, 1071

(4) (a) Yamguchi, M.; Sotokawa, T.; Hirama, M. Chem. Commun. 1997, 743 (b) Klaps, E.; Schmid, W. J. Org. Chem. 1999, 64, 7537. Allylmetalation of silylacetylenes is often not stereoselective: (c) Fujiwara, N.; Yamamoto, Y. J. Org. Chem. 1997, 62, 2318. (d) Molander, G. A. J. Org. Chem 1983, 48, 5409.

(5) For selected examples of metal-catalyzed cis-allylmetalation, see: (a) Okada, K.; Oshima, K.; Utimoto, K. J. Am. Chem. Soc. 1996, 118, 6076. (b) Shirakawa, E.; Yamasaki, K.; Yoshia, H.; Hiyama, T. J. Am. Chem. Soc. 1999, 121, 10221. (c) Nishikawa, T.; Yorimitsu, H.; Oshima, K Synlett 2004, 1573. For a review, see: (d) Yamamoto, Y.; Asao, N. Chem. Rev. 1993, 93, 2207

(6) (a) Sherry, B. D.; Toste, F. D. J. Am. Chem. Soc. 2004, 126, 15978. (b) Suhre, M. H.; Reif, M.; Kirsch, S. F. Org. Lett. 2005, 7, 3925. (c) Binder, J. T.; Kirsch, S. F. Org. Lett. 2006, 8, 2151. (d) Sherry, B. D.; Maus, L.; Lafortezza, B. N.; Toste, F. D. J. Am. Chem. Soc. 2006, 128, 8132. For a review of cyclization-induced rearrangements, see: (e) Overman, L. E. Angew. Chem., Int. Ed. Engl. 1984, 23, 579.

(7) For a recent report of $\mathrm{Au}(\mathrm{III})$-catalyzed reactions of allylsilanes, see: Georgy, M.; Boucard, V.; Campagne, J.-M. J. Am. Chem. Soc. 2005, 127 14180 .

(8) (a) Fernández-Rivas, C.; Méndez, M.; Echavarren, A. M. J. Am. Chem Soc. 2000, 122, 1221. (b) Fernández-Rivas, C.; Méndez, M.; NietoOberhuber, C.; Echavarren, A. M. J. Org. Chem. 2002, 67, 5197. For an endo-selective intramolecular trans-addition of allylsilanes to alkynes, see: (c) Imamura, K.; Yoshikawa, E.; Gevorgyan, V.; Yamamoto, Y. J. Am. Chem. Soc. 1998, 120, 5339.

(9) Under identical conditions, $\left(\mathrm{Ph}_{3} \mathrm{P}\right) \mathrm{AuCl}$ required $10 \mathrm{~h}$ to afford $72 \%$ yield of 2a. On the other hand, no reaction was observed on treatment of $\mathbf{1}$ with $\mathrm{AgSbF}_{6}, 10 \% \mathrm{AgSbF}_{6} / 4 \% \mathrm{PPh}_{3}, \mathrm{PtCl}_{2}$, or $(\mathrm{PhCN})_{2} \mathrm{PdCl}_{2}$.

(10) Reaction of $\mathbf{3}$ with $\left(\mathrm{Ph}_{3} \mathrm{P}\right) \mathrm{AuCl} / \mathrm{AgBF}_{4}$ gave $\mathbf{4 a}$ and $\mathbf{5 a}$ in 15 and $7 \%$ yield, respectively. No reaction was observed on treatment of $\mathbf{3}$ with $\mathrm{AgSbF}_{6}, \mathrm{AgBF}_{4}, \mathrm{PtCl}_{2},(\mathrm{PhCN})_{2} \mathrm{PdCl}_{2},(\mathrm{PhCN})_{2} \mathrm{PdCl}_{2} / \mathrm{AgBF}_{4}$, or CuOTf

(11) Ma, S.; Yu, S.; Gu, Z. Angew. Chem., Int. Ed. 2005, 45, 200.

(12) The allyl analogue of $6 \mathbf{i}\left(\mathrm{R}^{1}=\mathrm{Ph} ; \mathrm{R}^{2}, \mathrm{R}^{3}=\mathrm{H}\right)$ did not undergo the gold(I)-catalyzed reaction with methanol and gave a complex mixture with phenol at $50{ }^{\circ} \mathrm{C}$

(13) Deuterium labeling is consistent with protonation of a vinylgold intermediate (see Supporting Information).

(14) (a) Hollis, T. K.; Bosnich, B. J. Am. Chem. Soc. 1995, 117, 4570. (b) Kim, K.-C.; Reed, C. A.; Elliot, D. W.; Mueller, L. J.; Than, T.; Lin, L.; Lambert, J. B. Science 2002, 297, 825. (c) Blumenkopf, T. A.; Overman, L. E. Chem. Rev. 1986, 86, 857 and references therein

(15) (a) Nieto-Oberhuber, C.; Muñoz, M. P.; Buñuel, E.; Nevado, C.; Cárdenas, D. J.; Echavarren, A. M. Angew. Chem., Int. Ed. 2004, 43, 2402. (b) Mamane, V.; Gress, T.; Krause, H.; Fürstner, A. J. Am. Chem. Soc. 2004 126, 8654. (c) Luzung, M. R.; Markham, J. P.; Toste, F. D. J. Am. Chem Soc. 2004, 126, 10858. (d) Zhang, L.; Kozmin, S. A. J. Am. Chem. Soc 2004, 126, 11807. (e) Nieto-Oberhuber, C.; López, S.; Echavarren, A. M. J. Am. Chem. Soc. 2005, 127, 6178. (f) Gorin, D. J.; Davis, N. R.; Toste, F. D. J. Am. Chem. Soc. 2005, 127, 11260. (g) Johansson, M. J.; Gorin, D. J.; Staben, S. T.; Toste, F. D. J. Am. Chem. Soc. 2005, 127, 18002

(16) (a) Tamao, K.; Kumada, H. Tetrahedron Lett. 1984, 25, 321. (b) Jones, G. R.; Landais, Y. Tetrahedron 1996, 52, 7599.

(17) Slutsky, J.; Kwart, H. J. Org. Chem. 1973, 38, 3658

(18) Reiser, O. Angew. Chem., Int. Ed. 2006, 45, 2838. JA0636800 